\title{
Efetividade dos Direitos Humanos e Democracia: a Soberania Constitucional Cooperativa entre a Ordem Estatal e a Ordem Internacional na Sociedade do RisCo E DA INFORMAC̣̃̃o
}

\section{Effectiveness of Human Rights and Democracy: Cooperative Constitutional Sovereignty between the State Order and the International Order in the Risk AND INFORMATION SOCIETY}

\section{Efectividad de los Derechos Humanos y Democracia: La Soberanía Constitucional Cooperativa entre el Orden Estatal y el Orden Internacional en la SOCIEDAD DEL RIESGO Y DE LA INFORMACIÓN}

Roberto Correia da Silva Gomes Caldas Carlos Alberto Simões de Tomaz**

\footnotetext{
"Bacharel em Direito, Mestre e Doutor em Direito do Estado, respectivamente em Direito Tributário e Administrativo, pela PUC/SP - Pontifícia Universidade Católica de São Paulo. Professor permanente dos Cursos de bacharelado e Mestrado em Direito do Centro Universitário das Faculdades Metropolitanas Unidas - FMU. Professor convidado dos Cursos de Mestrado e Doutorado da UNICURITIBA. Professor licenciado da Faculdade Paulista de Direito, da PUC/SP - Pontifícia Universidade Católica de São Paulo. Professor permanente dos Cursos de Maestría en Derecho de las RRII y de la Integración en América Latina de la UDE - Universidad de la Empresa Montevidéu/Uruguai, e de "Master" em Direito sobre "Contratación pública sostenible" na Faculdad de Ciencias Jurídicas y Sociales de Toledo da UCLM - Universidad de Castilla-La Mancha. "External Researcher" da Cátedra Jean Monnet em Direito da UFMG - Universidade Federal de Minas Gerais. Coordenador da Rede de Pesquisa "Integração, Estado e Governança”. Diretor de Relações Institucionais do IASP - Instituto dos Advogados de São Paulo. Advogado em Portugal e no Brasil. São Paulo/SP/Brasil. E-mail: <robertocsgcaldas@uol.com.br>. http://orcid. org/0000-0003-0772-4450

"Pós-doutor em Filosofia do Direito pela Universidade de Coimbra. Doutor em Direito pela Universidade do Vale do Rio dos Sinos - UNISINOS/RS. Mestre em Direito das Relações Internacionais pelo Centro Universitário de Brasília - UniCEUB/DF. External Researcher do Centro de Excelência Jean Monnet em Direito da UFMG - Universidade Federal de Minas Gerais. E-mail: <ca.tomaz@uol.com.br>.http://orcid.org/0000-0003-4616-9138
} 
1 Introdução. 2 A projeção interna e externa da soberania constitucional em face do novo arranjo cooperativo da ordem estatal. 3 A projeção externa da soberania constitucional cooperativa: centro, periferia e sociedade/comunidade global heterárquica. 4 Conclusão. Referências.

\section{RESUMO}

Objetivo: $O$ artigo tem por escopo analisar a projeção da soberania constitucional cooperativa no âmbito interno dos Estados e na ordem internacional da contemporânea sociedade do risco e da informação, tendo como preocupação a efetividade dos direitos humanos ou fundamentais (ou ambos), para questionar a vivência democrática numa e noutra ordem.

Metodologia: Segundo uma metodologia própria para lidar com temas interdisciplinares específicos, como de Direito Internacional, da Integração, Constitucional e Sociologia Jurídica, parte-se de um recorte crítico da realidade exposta, tendo-se como marco teórico a doutrina contemporânea referida, ao adotar-se o método dedutivo, com apoio da exploração bibliográfica e documental enquanto técnica de abordagem, para se comprovarem as premissas levantadas e se alcançarem os objetivos propostos.

Resultados: Divisa, sob tal contextura, a perda do monopólio estatal de criação e aplicação normativas, com a exsurgência de novos polos definidores de conteúdos (nocivos e benignos) que ensejam profundas modificações tanto no plano interno quanto no plano externo, em que a atuação dos mais variados agentes - entre eles, e ainda com centralidade, o Estado - ampara-se em operações transjuncionais que marcam a hipertrofia dos sistemas econômico e político em detrimento da autonomia do sistema jurídico, o que se erige em prejuízo da efetividade dos direitos humanos ou fundamentais (ou ambos).

Contribuições: $\mathrm{O}$ estudo aponta, segundo a metodologia adotada, a soberana função sistêmico-integradora da Constituição que se apresentaria, na atualidade, como um espaço normativo voltado a permitir uma salutar inter-referência entre os sistemas jurídico, político e econômico, de maneira a ter-se, em conclusão, um canal heterárquico e cooperativo de equalização dos interesses recíprocos no concerto democrático.

Palavras-chave: Soberania Constitucional Cooperativa. Ordens Democráticas Interna e Internacional. Efetividade dos Direitos Humanos/Fundamentais. Sistemas Político, Econômico e Jurídico. Sociedade do Risco e da Informação.

\section{ABSTRACT}

Objective: The article aims to analyze the projection of cooperative constitutional sovereignty in the internal ambit of the States and in the international order of the 
Efetividade dos direitos humanos e democracia: a soberania constitucional cooperativa entre a ordem estatal e a ordem internacional na sociedade do risco e da informação

contemporary society of risk and information to question the democratic experience in one order and another, having as concern the effectiveness of human or fundamentals rights (or both).

Methodology: According to an appropriate methodology to deal with specific interdisciplinary themes, such as International Law, Integration Law, Constitutional Law and Legal Sociology, it is from a critical view of the exposed reality, taking as a theoretical framework the contemporary doctrine referred to, when adopting the deductive method, with the support of bibliographic and documentary exploration as an approach technique, to prove the premises raised and to achieve the proposed objectives.

Results: Under such a context, the paper identifies the loss of the state monopoly of normative creation and application with the exsurgency of new defining poles of noxious and benign contents that lead to profound changes in both orders, internal and international, where the performance of the most varied agents - between them, and still with centrality, the State - sustains on transjunctional operations that mark the hypertrophy of the economic and political systems to the detriment of the autonomy of the legal system, which is erected to the harm of the effectiveness of human or fundamentals rights (or both).

Contributions: The article notes, according to the adopted methodology, the systemicintegrating sovereign function of the Constitution that would present itself, nowadays, as a normative space aimed at allowing a healthy inter-reference between the legal, political and economic systems, in order to have, in conclusion, a heterarchic and cooperative channel for equalizing reciprocal interests in the democratic concert.

Keywords: Cooperative Constitutional Sovereignty. Internal and International Democratic Orders. Effectiveness of Human/Fundamental Rights. Political, Economic and Legal Systems. Risk and Information Society.

\section{RESUMEN}

Objetivo: El artículo tiene como objetivo analizar la proyección de la soberanía constitucional cooperativa en la esfera interna de los Estados y en el orden internacional de la sociedad contemporánea del riesgo y de la información, teniendo como preocupación la efectividad de los derechos humanos o fundamentales (o ambos), para cuestionar la experiencia democrática en uno y otro orden.

Metodología: De acuerdo con una metodología adecuada para tratar temas interdisciplinarios específicos, como Derecho Internacional, de la Integración, Constitucional y de la Sociología Jurídica, se ha partido de una visión crítica de la 
realidad expuesta, teniendo la doctrina contemporánea mencionada como marco teórico, al adoptar el método deductivo, con el apoyo de la exploración bibliográfica y documental como técnica de aproximación, para probar las premisas planteadas y alcanzar los objetivos propuestos.

Resultados: Bordea, en este contexto, la pérdida del monopólio estatal de creación y aplicación normativa con la exsurgencia de nuevos polos que definen el contenido (perjudiciales y benignos) y que conducen a cambios profundos, tanto en el plan interno como externo, donde el desempeño de los más variados agentes - entre ellos, y aún centralmente, el Estado - se basa en operaciones transjuncionales que marcan la hipertrofia de los sistemas económicos y políticos en detrimento de la autonomía del sistema jurídico, que se erige en perjuicio de la efectividad de los derechos humanos o fundamentales (o ambos).

Contribuiciones: El estudio señala, según la metodología adoptada, la soberana función de integración sistémica de la Constitución que se presentaría, hoy por hoy, como un espacio normativo destinado a permitir una sana interreferencia entre los sistemas jurídicos, políticos y económicos, a fin de tener, en conclusión, un canal heterárquico y cooperativo de ecualización de intereses recíprocos en el concierto democrático.

Palabras clave: Soberanía Constitucional Cooperativa. Órdenes Democráticas Internas e Internacionales. Efectividad de los Derechos Humanos/Fundamentales. Sistemas Políticos, Económicos y Legales. Sociedad del Riesgo y de la Información.

\section{INTRODUÇÃO}

A projeção da soberania constitucional no âmbito interno dos Estados e na ordem internacional da contemporânea sociedade do risco e da informação, tendo como preocupação a efetividade dos direitos humanos ou fundamentais (ou ambos), para questionar a vivência democrática numa e noutra ordem, em si, para além das indagações sobre ser necessário que os Estados sejam democráticos para que a ordem internacional o seja, bem como sobre ser possível a ordem internacional global se tornar democrática independentemente de alguns Estados não o serem, estabelece a necessidade do exercício dessa soberania de maneira mais adequada à realidade (heteráquica) dos dias atuais.

Para tanto, a influência da soberania constitucional na ordem interna estatal é analisada sob o prisma do novo arranjo concertado em que se funda a hodierna relação jurídica de Administração Pública, de sorte a se verificar como que essa soberania se encontra exposta na ordem jurídica dos Estados, marcadamente à luz da perda do monopólio por parte deste na criação e na aplicação normativas, ante a concorrência de outros polos definidores de conteúdos que têm se apresentado ora nocivos, como os 
Efetividade dos direitos humanos e democracia: a soberania constitucional cooperativa entre a ordem estatal e a ordem internacional na sociedade do risco e da informação

advindos de organizações criminosas e cartéis econômicos, e ora benignos, conforme os decorrentes de distintos setores privados com suas autorregulações que, por vezes, são institucionalizadas, galgando o status de uma governança pública regulatória participativa.

Por outro lado, quando levada a análise para a projeção da soberania constitucional no plano externo, verifica-se que, da mesma maneira que no plano interno, a autonomia do Direito padece frente às ingerências da Política e da Economia que desbordam do inter-relacionamento salutar que deveria nortear as relações intersistêmicas, o que somente pode ser contornado à luz de um Direito geral de cooperação häberlesiano entre Estados (e entre estes e suas sociedades) no seio de uma comunidade global comprometida com a realização dos direitos humanos/fundamentais.

Nesse âmbito, ou seja, numa ordem internacional caracterizada pela ausência de um polo nômico supremo - o que coloca novas luzes no conceito de soberania -, a convivência de vários polos públicos e privados benignos de poder (v. g., a ONU com suas distintas organizações internacionais, além das instituições privadas transnacionais e entidades representativas da sociedade civil - in casu, criadoras de global governance e autorregulação setorial global, como os Princípios do Equador, Princípios Orientadores sobre Empresas e Direitos Humanos das Nações Unidas, Declaração Tripartite de Princípios sobre Empresas Multinacionais e Política Social etc.), em paralelo, não se pode deixar de registrar, com outras distintas poderosas redes criminosas e, por isso, nocivas (as quais implicam corrupção e cooptação de agências reguladoras a prol de interesses particulares, entre outros ilícitos), com ambos os referidos segmentos sendo notadamente vinculados aos sistemas econômico e político, a sua vez, transforma a ordem internacional numa ordem global, multilateral, heterárquica, policêntrica e, assim, multifacetada, que se convencionou acoimar de multi-stakeholderism.

Nesse espaço, as relações entre os polos heterárquicos desenvolvem-se por meio de operações transjuncionais que prejudicam a concreção dos direitos humanos e/ou fundamentais, tal qual acontece na ordem constitucional dos Estados, os quais, por isso, se veem sufocados pela hipertrofia da atuação desses referidos polos e seus correlatos sistemas (heterárquicos), em claro detrimento de uma maior inclusão social.

Uma institucionalização/programação tanto interna quanto internacional para, em nome do concerto democrático de uma soberania constitucional cooperativa, proceder aos ajustes necessários em defesa da inclusão social e, assim, da mais ampla efetivação dos direitos humanos/fundamentais, é o que os Estados devem procurar, inclusive segundo uma governança resiliente concertada (global e regulatória) que se mostre adaptativa/transformadora das estruturas organizacionais e procedimentais dos distintos atores, bem como capaz, inclusive, de permitir se identificar quais destes são 
nocivos a tal inclusão social alvitrada, eliminando-os ou afastando-os em um processo dialógico definidor dos conteúdos a serem discutidos. Tornar evidente tais problemas objeto deste artigo - já é um ponto de partida significativo.

Desse modo, o artigo se valeu para tal mister do método dedutivo, partindo de um recorte crítico da realidade exposta, de pesquisa bibliográfica em sua técnica de abordagem, tendo como referencial teórico a teoria dos sistemas de Luhmann (2002), com os desdobramentos teoréticos de Neves (2006) e Teubner (2003), bem como a concepção de soberania constitucional exposta por Voigt (2013) sob o influxo do constitucionalismo cooperativo de Häberle (2007), à luz de uma metodologia própria para se expor de que forma a soberana função sistêmico-integradora da Constituição, devidamente conformada à nova ordem global, a apresentaria como um espaço normativo voltado a uma salutar inter-referência entre os sistemas jurídico, político e econômico, de sorte a ter-se, em conclusão, um canal heterárquico e cooperativo de equalização dos interesses recíprocos no concerto democrático.

\section{A PROJEÇÃO INTERNA E EXTERNA DA SOBERANIA CONSTITUCIONAL EM FACE DO NOVO ARRANJO COOPERATIVO DA ORDEM ESTATAL ${ }^{1}$}

O pluralismo jurídico-político imprime, sem dúvida, uma perda da significação do Estado em sua concepção clássica, bem como introduz sensíveis alterações na ordem interna e internacional. Efetivamente, o enfrentamento e o enfraquecimento da capacidade de o Estado definir sozinho os conteúdos normativos e decidir sobre o modo de sua aplicação tem revelado um lado muito preocupante da crise estatal vivenciada em sua contemporânea sociedade do risco, sistêmico e reflexivo, conforme explicitado por Lourenço (2019), e da informação, em rede, tecnológica e veloz, consoante lecionado por Castells (2002).

Não há como negar a fragilidade a que se encontra exposto, nos dias atuais, aquele que foi o centro de irradiação de decisões políticas e jurídicas e que, ainda, apresentava-se como o locus de exclusividade na definição dos seus conteúdos, de tal maneira que não admitia, no plano interno, poder sequer igual ou capaz de influenciá-lo nessa função, além de, no plano internacional, apenas reconhecer outros de iguais poderes para garantir, assim, uma convivência harmônica nessa ordem.

A irradiação da soberania nessa conformidade, como bem informa Cavalcanti (1900), encontra eco desde o pensamento medieval de Bodin (1966) e Grotius (2005), os quais a concebiam como poder supremo que não admitia nenhum outro maior que si (suprema potestas superiorem non recognoscens); todavia, tal paradigma de soberania,

\footnotetext{
${ }^{1}$ As ideias contidas nesse tópico se verificam anteriormente tratadas, de forma isolada, em Tomaz (2011) e Tomaz (2016), e, conjuntamente, em Tomaz e Lages (2015), sendo ora desenvolvidas e, assim, apresentadas com acréscimos, revisões e modificações.
}

54 - R. Opin. Jur., Fortaleza, ano 18, n. 29, p.49-76, set./dez. 2020 
Efetividade dos direitos humanos e democracia: a soberania constitucional cooperativa entre a ordem estatal e a ordem internacional na sociedade do risco e da informação

enquanto um poder absoluto, perpétuo, indivisível, inalienável e imprescritível (BODIN, 1966), ou seja, um poder incontrastável de mando, em âmbito interno e internacional, não mais se compraz e sustenta diante da realidade das relações internas e internacionais hodiernas.

É preciso ter-se presente, assim, que a soberania se extroverte sob distintas formas com respeito à fundamentação e à execução, as quais, segundo Voigt (2013), são definidas em cada Estado como sendo parlamentar, constitucional (jurídica) e do povo (direta), segundo um critério distintivo entre o seu sujeito (Estado) e seu portador (povo), consoante entendimento que se mostra a partir, e indo para além, do de Heller (1995), o qual, a seu turno, é fundamentado na teoria hegeliana de Estado, visto enquanto a instância suprema de positivação de normas e, repita-se, sujeito da soberania.

Com efeito, sob a forma jurídica de execução, a ideia de um poder soberano cuja legitimação e limites encontram-se exclusivamente na norma por ele criada e aplicada de modo impessoal - ou seja, dentro do domínio normativo de acordo com a visão preconizada por Kelsen $(1992)^{2}$-, em si, entra em confronto com a hodierna necessidade de convivência com outras forças regulatórias dos distintos setores da sociedade, cuja legitimidade também se espraia em uma perspectiva internacional, a qual, inclusive, antes era vista de atuação exclusiva do Estado (OLSSON; LAVALL, 2020). Dentro da visão kelseniana, soberano seria apenas o

Estado cuja ordem jurídica fosse o ponto de partida de toda sua estrutura [...] $\bigcirc$ Direito Internacional é válido apenas por ser reconhecido pelo Estado mencionado em primeiro lugar, o qual é soberano porque a ordem jurídica internacional é considerada parte de sua ordem jurídica e, portanto, inferior a ela (KELSEN, 1992, p. 373).

Dessa forma, a postura estatal kelseniana de exercício da soberania, principalmente a partir da última década do século XX, não mais se coaduna com a realidade dos dias atuais em que vários outros distintos focos emissores de conteúdo normativo (nacionais e estrangeiros) exsurgem em concomitância ao irrompimento do fenômeno da globalização, no qual o exercício desse poder soberano do Estado se verifica entrelaçado num amálgama decorrente da multiplicidade de relações

\footnotetext{
${ }^{2}$ A Escola de Viena apontava para a circunstância de que é pressuposto de uma posição monista, com primazia do Direito estatal sobre o Direito Internacional (monismo nacionalista), a soberania absoluta do Estado. Daí porque, afastando o monismo nacionalista e adotando o monismo internacionalista, Kelsen, não obstante divisasse a soberania como qualidade de uma ordem normativa, já abria espaço para uma concepção aberta quando afastava o solipsismo de Estado, o que pressupõe, obviamente, inter-referência, todavia, tomada apenas no campo da normatividade do Direito Internacional (KELSEN, 1992).
} 
concorrentes, as quais, inclusive, não se projetam exclusivamente no campo normativo, mas também político e econômico.

Atento a esse aspecto multidimensional de projeções da multiplicidade de relações em que o Estado se verifica hoje envolvido, Ferrajoli (2002, p. 1), de início, já chama a atenção para o fato de que a "soberania é um conceito ao mesmo tempo jurídico e político, em torno do qual se adensam todos os problemas e aporias da teoria juspositivista do direito e do Estado."

Deveras, assim como o próprio Direito não pode mais ser compreendido sob uma visão exclusivamente normativista kelseniana, porque legitimado e operado mercê de um complexo de relações de inter-referências que implicam competição e enfrentamento social por parte de numerosas e heterogêneas forças sociais (ZAGREBELSKY, 2011), a soberania (sob uma óptica constitucional, jurídica) igualmente não pode ser mais concebida, legitimada e operada segundo um sistema jurídico hermeticamente fechado e estático, no qual o Estado é considerado absoluto e como fonte exclusiva de criação e aplicação normativa (LAFER, 1995). De acordo com este autor

A lógica da Paz de Westfália que comporta, em tese, a noção de soberania absoluta, não é compatível com as realidades contemporâneas e o seu direito internacional, pois existem contradições entre ela e a experiência. A primeira, que é constitutiva, reside na igualdade das soberanias, em teoria, e na sua desigualdade, na prática. A segunda, que se tornou avassaladora neste final de milênio, é a impossibilidade do isolamento, que vem levando à interdependência dos Estados e ao transnacionalismo dos atores da vida mundial - transnacionalismo não apenas dos mercados e dos agentes econômicos, mas também dos meios de comunicação, da opinião pública, das organizações nãogovernamentais. Daí a necessidade do mútuo reconhecimento das soberanias, as exigências de cooperação através das organizações internacionais e o multilateralismo das normas de mútua colaboração e o fato de as soberanias se verem permeadas pela ação transnacional da qual é exemplo a nova "lex mercatória" (LAFER, 1995, p. 140)

É por isso que, conforme informado por Lafer (1995) em outra passagem, à luz da teoria de Grotius sobre a convivência internacional dos Estados (fundada na existência de um potencial de socialidade e solidariedade da sociedade global), na atualidade, tem-se a atribuição de competências próprias das soberanias estatais a instituições supranacionais (com sua clara limitação), segundo a ideia de interdependência (supra, inter e infra-estatal) e funcionalismo em prol de um espontâneo cooperativismo - nos dizeres de Häberle (2007), constitucional multilateral para uma construtiva reciprocidade de interesses comuns, consoante se extrai do processo de integração econômica mais bem sucedido, a União Europeia. 
Efetividade dos direitos humanos e democracia: a soberania constitucional cooperativa entre a ordem estatal e a ordem internacional na sociedade do risco e da informação

A partir daí, divisa-se uma concepção aberta da soberania constitucional globalizada para havê-la cooperativa e mesclada numa rede de inter-referências sociais partindo do sistema jurídico para os sistemas político e econômico, sendo, assim, entendida como forma de comprometimento conjunto dos Estados e das organizações não governamentais em prol da efetivação dos direitos humanos e/ou fundamentais em uma sociedade da informação marcada pela insegurança decorrente dos riscos insertos a tal cotidiana realidade (HÄBERLE, 2007). Nesse contexto, segundo Andreucci (2019, p. 47)

\begin{abstract}
Esta hiper-sociedade, pós, líquida, e imersa no risco, redefiniu relações de sociabilidade, prioridades políticas, econômicas, empresariais, nacionais, supranacionais sem, contudo, assentar os novos rumos e paradigmas de maneira segura. $\mathrm{O}$ debate, assumindo sua condição pósmoderna, e na qual o termo globalização se faz quase sempre presente, torna-se também aberto, fragmentário, líquido, pressupondo o risco. Uma das características desta nova realidade pode ser observada numa outra qualidade atribuída ao tempo e ao espaço. Os deslocamentos e as fronteiras tornam-se mais difusos e a dimensão planetária passa a ser um fator determinante na reconstrução do Estado-Nação.
\end{abstract}

Essa visão de maior amplitude da soberania constitucional, tida como cooperativista e concebida a partir do processo de mundialização (dito, mais comumente, globalização), requer, não obstante, uma atenção redobrada, uma vez que tal processo, por ensejar o aparecimento dos referidos distintos polos emissores de conteúdo normativo em exercício direto do poder (soberania popular), permite que, dentre eles, alguns se revelem nocivos e outros benignos à manutenção da ordem pública nacional e internacional globalizante pré-estabelecida (ZAGREBELSKY, 2011).

É nesse contexto que Voigt (2013), após versar sobre as distintas formas de soberania por ele alvitradas (parlamentar, constitucional e do povo), procede à sua crítica da soberania, asseverando que quanto ao seu viés global contemporâneo, à luz da doutrina de Hardt e Negri (2000), está-se diante de um "estado de guerra global" descrito por Virilio (1996) como um "estado de emergência”, à luz da "guerra da informação" e do movimento de globalização -, cuja violência que dele pode eclodir os Estados nacionais não são capazes (ou fortes o suficiente) para sozinhos suplantarem, decorrendo, por isso, a necessidade de uma nova forma de soberania neste âmbito, a multitude, que, não sendo nem o povo, nem a massa, nem alguma formação de classe trabalhadora, é composta de numerosas diversidades sociais internas que podem nunca ser reduzidas a uma unidade ou identidade singular, embora não se revele fragmentada, anárquica ou desconexa, moldando a sociedade de modo autodeterminado.

Não obstante a acepção de multitude proposta por Hardt e Negri (2000) careça de um núcleo essencial característico com maior densificação, a permitir que possa ser 
especificado para uma aplicação conceitual melhor discernida, dela aproveita-se a concepção de uma inerente capacidade de se autogovernar, preservando, assim, suas pluralidade e diversidade irredutíveis ante a identificação em si de atos multitudinários em um cenário nacional e internacional, criando, de conseguinte, um espaço "comum" de emancipação do exercício global de poder, conforme salientam tanto Browning e Kilmister (2006), como também o próprio Voigt (2013).

Há de se registrar, ainda, a relevância dessa noção de multitude estabelecida à luz de uma soberania popular exercida ao influxo do hodierno Estado constitucional cooperativo (HÄBERLE, 2007), porquanto, ao terem-se suas pluralidade e diversidade como irredutiveis, permite afastar-se o efeito excludente da globalização quanto a certas vulnerabilidades ou grupos que não se adaptem a si e às suas imposições uniformizadoras, as quais assumem, assim, o feitio de uma tendência ainda em construção num conjunto de processos cumulativos, consoante ressaltado, entre outros, por Castells (2001), Andreucci (2019) e Andreucci e Nohara (2011).

Porém, apesar dessa concepção de multitude quanto à preservação das pluralidades e das diversidades sociais (para considerá-las irredutíveis), bem como à possibilidade que encerra de se afastarem os efeitos excludentes advindos da globalização, é preciso não se olvidar que tal nova forma global de exercício da soberania não impede que aquelas antes mencionadas forças normativas nocivas, a exemplo do crime organizado, rompam as fronteiras do Estado nacional com a mesma amplitude do capital, ciência, tecnologia e cultura, galgando a esfera internacional.

A existência de redes criminosas internacionais, v. g., voltadas a disseminar a violência e o tráfico de entorpecentes, órgãos, crianças, mulheres, armas e capital ilícito, inclusive mediante corrupção e cooptação de agências regulatórias, é fato comprovado. Segundo Castells (2002, p. 40)

[...] as atividades criminosas e organizações ao estilo da máfia de todo o mundo também se tornaram globais e informacionais, propiciando meios para o encorajamento de hiperatividade mental e desejo proibido, juntamente com toda e qualquer forma de negócio ilícito procurado por nossas sociedades, de armas sofisticadas à carne humana.

E, em contraponto a tais vitandas forças normativas nacionais e internacionais, para fazer face a esse fenômeno, tem-se o vicejamento das redes protetivas de atuação regulatória autônoma em áreas não alcançadas pela legislação estatal - atuação, esta, vista como "governança sem governo" (ROSENAU, 2000) ou, simplesmente, autorregulação -, se expressando sob as mais variadas organizações não governamentais, em uma multiplicidade de esforços e fontes, em cujo contexto, embebido na concepção de Estado constitucional cooperativo (HÄBERLE, 2007) e de uma cidadania de extensão internacional (BOLZAN DE MORAIS, 2011; BOLZAN DE MORAIS, 
Efetividade dos direitos humanos e democracia: a soberania constitucional cooperativa entre a ordem estatal e a ordem internacional na sociedade do risco e da informação

NASCIMENTO, 2010), evidencia a ação de distintos atores em setores variados, como a ecologia (Greenpeace), a defesa dos direitos humanos (Anistia Internacional) e a promoção da saúde (Médicos Sem Fronteiras), a revelar uma nova forma de multilateralismo, o multi-stakeholderism (BENEDEK, 2011), o qual, embora não substitua as formas tradicionais multilaterais, as complementa, garantindo estruturas de governança mais inclusivas, conforme informam Olsson e Lavall (2020).

Esse amálgama de inter-referências, como se vê, ora se desenvolve em amparo ao processo democrático, buscando a inserção do indivíduo e a integração de comunidades ao escopo de tutelar e ensejar a eficácia, a eficiência e a efetividade dos direitos humanos/fundamentais, e ora se desenvolve exatamente ao fito contrário. Sobre tal circunstância, Zagrebelsky (2011, p. 38-39) assevera

Además de ser consecuencia del pluralismo político-social que se manifiesta en la ley del Parlamento, los ordenamientos actuales también son el resultado de una multiplicidad de fuentes que es, a su vez, expresión de una pluralidad de ordenamientos "menores" que viven a la sombra del estatal y que no siempre aceptan pacíficamente una posición de segundo plano. A este respecto, se ha hablado de "gobiernos particulares" o "gobiernos privados" que constituyen ordenamientos jurídicos sectoriales o territoriales. De tales ordenamientos, algunos pueden considerarse enemigos del estatal y ser combatidos por ellos, pero otros pueden ser aceptados para cuncurrir con las normas estatales en la formación de un ordenamiento de composición plural. De este modo, la estabilidad del derecho, que era una premisa esencial del positivismo jurídico del siglo pasado, es puesta en tela de juicio y la ley se retrae con frecuencia para dejar sectores enteros a regulaciones de origen diversos, provenientes bien de sujetos públicos locales, en conformidad con la descentralización política y jurídica que marca de forma característica la estructura de los Estados actuales, bien la autonomía de sujetos sociales colectivos, como los sindicatos de trabajadores, las asociaciones de empresarios y las asociaciones profesionales.

Aqui, vê-se travada uma verdadeira batalha. Essa luta, no plano interno, tende a propiciar a consolidação do Estado Democrático de Direito, por meio de uma adequada relação entre governo e jurisdição, que redunda para além da submissão do exercício da soberania aos limites normativos, alcançando a admissão, o controle e a gestão dos novos atores cuja atuação se volte para imprimir uma maior legitimação do poder do Estado, de tal sorte que o arranjo democrático se apresente mais eficaz e eficiente no caminho da efetivação dos direitos humanos e/ou fundamentais, não resultando, apenas, em num arranjo formal (TOMAZ; MATA DIZ; CALDAS, 2019). O ajuste daí resultante permite uma reorientação conceitual para a liberdade bem desvelada por Maia (2011, p. 38) quando registra que 
A democracia é o ajuste político proposto quando a igualdade de condições material está inexoravelmente perdida pelo reconhecimento da naturalidade (no sentido contratualista) com que desenvolvemos a ideia e o sentimento de apropriação individual. E a liberdade, revisitada, deve se manifestar como uma igualdade de oportunidades, que devem ser livremente assumidas por cada um, ou seja, a liberdade ética.

Assim, desde que a norma (constitucional) resulte de um conserto novo por meio de revelar a vontade da maioria dos a ela concernidos, avultar-se-á, desde aí, soberana, de tal sorte que esse círculo garantiria a legitimidade e resolveria uma possível antinomia entre a soberania e a sua limitação jurídica. Ferrajoli (2002, p. 40) reproduz essa visão ao fazer ver que

Essa antinomia, como já se viu, resolveu-se no plano do direito interno
com o nascimento do estado constitucional de direito, em virtude do
qual o direito regula a si próprio, impondo à sua produção vínculos não
mais apenas formais, ou seja, relativos às suas formas, mas também
substanciais, ou seja, relativos aos seus conteúdos, e assim
condicionando não mais apenas o vigor das normas produzidas,
mediante normas sobre os procedimentos, mas também sua validade
substancial, mediante normas sobre os direitos fundamentais. No
estado de direito, portanto, não existe nenhum soberano, a menos que
não se entenda como "soberana", como puro artifício retórico, a
própria constituição, ou melhor, o sistema de limites e de vínculos
jurídicos por ela impostos aos poderes públicos já não mais soberanos.

De fato, a configuração do Estado Democrático de Direito afasta a ideia de poderes soberanos pela própria autolimitação que o Direito, a ele próprio, impõe. Caso queira, soberana seria a Constituição, considerada dinâmica, enquanto um processo ideológico-cultural que prestigie e fomente sua programação política nas estruturas sociais que visa a reger de forma preponderante, criando um engajamento intenso dos a elas concernidos, com a abertura de canais para sua participação e cooperação (GUERRA FILHO, 1997).

Não é por outra razão que, ao analisar as relações entre democracia, direitos humanos/fundamentais e Estado constitucional, Pagliarini (2006, p. 22) registra que a Constituição "veio ao mundo para cumprir dois papéis históricos: (i) o de limitar o exercício do Poder, estruturando a comunidade política chamada Estado; (ii) o de proclamar e garantir direitos básicos do indivíduo."

E, dentro dessa composição dos papéis históricos da Constituição, é que avulta a importância de sua função soberana de acoplamento estrutural e estruturante entre os distintos subsistemas sociais, segundo uma maior autonomia e responsabilização destes 
Efetividade dos direitos humanos e democracia: a soberania constitucional cooperativa entre a ordem estatal e a ordem internacional na sociedade do risco e da informação

obtida com auxílio de mecanismos de consenso e participação, sob uma visão autopoiética do Direito há muito registrada por Caldas (1997, p. 214)

É com atenção às dificuldades havidas para se equacionar as mais variadas desarticulações sociais (encontrar o equilíbrio entre consenso e conflito), desarticulações estas impregnadas com marcante conotação política pela colocação em cena da liberdade individual da autoridade estatal, é que, inserida na teoria sistêmica, a teoria da autopoiese aparece como uma estratégia de busca do melhor modo de se controlar e manter a ordem social. Visa uma maior autonomia com maior responsabilização dos subsistemas do corpo social, cuja autodisciplina responsável, ou autogestão dos grupos sociais só se obtém por meio de mecanismo de consenso e de participação [...].

Dessa forma, posta a tessitura em que se insere a projeção interna e externa da soberania constitucional em face do novo arranjo cooperativo da ordem estatal, a qual, por seu turno, se mostra voltada a regrar as vicissitudes verificadas na contemporânea sociedade do risco e da informação, passa-se à análise da projeção externa de tal referida soberania constitucional dos Estados, considerados enquanto centrais e periféricos em uma ordem global concebida à luz de uma sociedade/comunidade heterárquica (TOMAZ, 2011).

\section{A PROJEÇÃO EXTERNA DA SOBERANIA CONSTITUCIONAL: CENTRO, PERIFERIA E SOCIEDADE/COMUNIDADE GLOBAL HETERÁRQUICA ${ }^{3}$}

O problema do exercício da soberania em um mundo globalizado, todavia, assume conotação diferente quando enfrentado em face da sua projeção em âmbito internacional, uma vez que caracterizado, como antes ressaltado, pela ausência de um polo nômico supremo, ou, em outras palavras, de uma norma legitimadora que igualmente imponha ao Estado vínculos formais e materiais, ensejadores de uma óptica da soberania de forma absoluta e unilateral.

De tal sorte, quando hoje se pretende estabelecer no plano externo um quadro formal e material, que se revele legitimador e garantidor da atividade estatal (ius cogens) o que implicaria e evidenciaria a antinomia entre soberania e Direito -, a discussão repousa em grande dificuldade e tem permitido assistir-se a certos retrocessos em nome de interesses nacionais, a exemplo do que ocorrido no âmbito do Direito da Integração quando não se obteve a unanimidade necessária entre os Estados europeus para a

\footnotetext{
${ }^{3}$ As ideias contidas nesse tópico se verificam anteriormente tratadas, de forma isolada, em Tomaz (2011) e Tomaz (2016), conjuntamente, em Tomaz e Lages (2015), sendo ora desenvolvidas e, assim, apresentadas com acréscimos, revisões e modificações.
} 
aprovação de uma Constituição da União Europeia, em um plano de supranacionalidade comunitária.

Com efeito, não obstante os processos de integração não seguirem uma linearidade evolutiva e ter-se chegado bem perto da promulgação de uma Constituição europeia (supranacional), tal circunstância, obviamente, quando transposta do Direito da Integração para o Direito Internacional Público, apenas se processaria segundo um acoplamento estrutural integrativo, como ressalta Ferrajoli (2002, p. 46), parodiando Dworkin $(2010)^{4}$, se se

'levar a sério' o direito internacional, e, portanto, assumir seus princípios como vinculadores e seu projeto normativo como perspectiva alternativa àquilo que de fato acontece; validá-los como chaves de interpretação e fontes de crítica e deslegitimação do existente; enfim, planejar as formas institucionais, as garantias jurídicas e as estratégicas políticas para realizá-los.

Enquanto isso não se efetiva, multiplicam-se as violações aos direitos humanos/fundamentais, à paz e à segurança, e outro caminho não se avulta além de se divisar e operar a soberania sob outro paradigma global, qual seja, o da soberania constitucional cooperativa, a qual envolve a concepção do chamado constitucionalismo cooperativo de Häberle (2007), inclusive à luz da concepção de global governance, alinhada à acepção lata de multitude desenvolvida por Hardt e Negri (2000).

De tal maneira, tem-se uma programação, uma diretriz de planejamento para se minimizarem os efeitos excludentes da globalização e se acompanhar o que acontece, o que existe: o desenvolvimento de núcleos de poder (não apenas estatal) hegemônicos e voltados para a atuação em rede de modo a infundir, difundir e perpetrar uma regulação global apta a influenciar e moldar condutas sociais, inclusive em âmbito interno, que sejam capazes de combater as mais atrozes violações ao princípio da dignidade humana, segundo um modelo de desenvolvimento sustentável mundialmente aceito, a exemplo do que hoje se verifica na Agenda 2030 (ONU, 2015) e no Pacto Global (ONU, 2019), instrumentos que podem ser considerados como pedras de toque, em conjunto com outras do gênero, do “direito comum de cooperação” häberlesiano (HÄBERLE, 2007).

É esse contexto, aliás, que revela o ambiente de mudanças em que o Estado nacional está atuando neste novo milênio da transnacionalidade. Assim, Hobsbawm aponta de forma precisa as profundas modificações que começaram a eclodir a partir do segundo pós-guerra

Quando a economia transnacional estabeleceu seu domínio sobre o mundo, solapou uma grande instituição, até 1945 praticamente

\footnotetext{
${ }^{4}$ Trata-se de uma referência ao título do livro Taking rights seriously - na tradução brasileira, Levando os direitos a sério.
}

62 • R. Opin. Jur., Fortaleza, ano 18, n. 29, p.49-76, set./dez. 2020 
Efetividade dos direitos humanos e democracia: a soberania constitucional cooperativa entre a ordem estatal e a ordem internacional na sociedade do risco e da informação

universal: o Estado-nação territorial, pois um Estado assim já não poderia controlar mais que uma parte cada vez menor de seus assuntos. Organizações cujo campo de ação era efetivamente limitado pelas fronteiras de seu território, como sindicatos, parlamentos e sistemas públicos de rádio e televisão nacionais, saíram portanto perdendo, enquanto organizações não limitadas desse jeito, como empresas transnacionais, o mercado de moeda internacional e os meios de comunicação da era do satélite, saíram ganhando. O desaparecimento das superpotências, que poderiam de qualquer modo controlar os Estados-satélites, iria reforçar essa tendência. Mesmo a mais insubstituível função que os Estados-nações haviam desenvolvido durante o século, a de redistribuir sua renda entre suas populações através das "transferências sociais" dos serviços de previdência, educação e saúde, e outras alocações de fundos, não mais podia ser territorialmente auto-suficiente em teoria, embora a maior parte tivesse de continuar sendo na prática, a não ser onde entidades supranacionais como a Comunidade ou União Europeias a complementasse em alguns aspectos. Durante o auge dos teólogos do livre mercado, o Estado foi solapado mais ainda pela tendência de desmontar atividades até então exercidas, em princípio, por órgãos públicos deixando-as entregues ao “mercado" (HOBSBAWM, 1997, p. 413-414).

Esse cenário impõe uma agenda programática de políticas públicas nacionais, regionais e globais, em um contexto de promoção de desenvolvimento sustentável, na qual o Estado aparece tomando ciência de que não mais detém o monopólio do Direito, ante a atuação heterárquica de antigos e novos atores (TOMAZ; LAGES, 2015) em um ambiente muito mais complexo e denso: uma autêntica rede, que constituiria a constelação pós-nacional desvelada por Habermas na antropocena (CRUTZEN; STOERMER, 2000) sociedade do risco e da informação

Assim como no século XIX o trem, o barco a vapor e o telégrafo intensificaram o trânsito de bens e das pessoas bem como a troca de informações, assim hoje em dia a tecnologia dos satélites, a navegação aérea e a comunicação digital criam novamente redes mais amplas e densas. "Rede" [Netzwerk] tornou-se uma palavra-chave, e tanto faz se se trata das vias de transporte para bens e pessoas, de correntes de mercadorias, capital e dinheiro, de transmissão e processamento eletrônicos de informações ou de circulações de pessoas, técnicas e natureza. Cadeias temporais comprovam as tendências globalizantes em muitas dimensões. O termo encontra igualmente aplicação na expansão intercontinental da telecomunicação, do turismo de massa ou da cultura de massa, bem como nos riscos transnacionais da técnica de ponta e do comércio de armas, nos efeitos colaterais mundiais do ecossistema explorado ou no trabalho conjunto internacional de organizações governamentais e não governamentais (HABERMAS, 2001, p. 84). 
A inter-relação, desse modo, entre a governança regulatória participativa ${ }^{5}$ e o exercício cooperativo da soberania constitucional em combate às violações aos direitos humanos e/ou fundamentais, e sua respectiva aplicação pelos sistemas globais, regionais e nacionais para promoção de um desenvolvimento sustentável legitimado pelos Estados e pelas suas sociedades, como visto, é determinada segundo um planejamento calcado não apenas em mecanismos institucionais e participativos em uma concepção bottom up (CALDAS, 2016; CALDAS; FREITAS, 2018), mas também a partir de pressupostos normativos exsurgidos do setor privado (como expressão de autorregulação social), e que, posteriormente, imbricam-se na forma de regulação do setor público, o qual os acaba institucionalizando, positivando e, assim, atribuindo-lhes cogência e não apenas legitimidade social (CALDAS; MARTINS, 2016).

Estabelece-se, com isso, um espectro de interconexão direta que acaba por fixar-se mediante medidas e atos normativos adotados pelos Estados e organizações internacionais, consequentemente, com uma influência persuasiva imbricada, sobreposta e direta na implementação e execução das atividades privadas de forma geral, mediante atos regulatórios de natureza obrigatória ou declaratória (soft law), enquanto expressão de uma regulamentação híbrida, nos dizeres de Hoffmann-Riem (2019), em um processo social reflexivo, dialético de globalização do local e localização do global, consoante os ensinamentos de Lourenço (2014), os quais revelam a interpenetração do Constitucionalismo cooperativo apontada por Häberle (2007).

Todavia, como acima já mencionado, a globalização tem imprimido uma legitimação do poder por intermédio de uma identidade imposta, padronizada e não diferenciada como aponta Castells (2001) e, na mesma direção, Andreucci (2019) e Andreucci e Nohara (2011).

Com efeito, Andreucci, inicialmente em conjunto com Nohara (2011), e, posteriormente, em trabalho isolado (2019), desenvolve o conceito de protoglobalização, consistente na construção de novos vínculos identitários em prol de uma comunidade global (e não mais sociedade - HÄBERLE, 2007), a partir da ideia de protonacionalismo de Hobsbawm (1990), para explicar os malefícios desse fenômeno uniformizador e excludente das diversidades que se mostrem incompatíveis com as tendências próprias do processo de globalização.

Por isso, ajustar os ditos Estados periféricos (HABERMAS, 2001; TEUBNER, 2003) à globalização tem implicado uma situação de exclusão, em que os direitos humanos/fundamentais e o princípio da dignidade humana têm sido postos de lado em face da sobrepujança de um unilateralismo massificante, a encerrar uma maldade líquida, nos dizeres de Bauman e Donskis (2019), a qual tem levado, v. g., à

\footnotetext{
${ }^{5}$ Sobre a diferença entre governança regulatória e governança corporativa, vide Caldas e Martins (2016) e Mata Diz e Caldas (2016).
}

64 - R. Opin. Jur., Fortaleza, ano 18, n. 29, p.49-76, set./dez. 2020 
Efetividade dos direitos humanos e democracia: a soberania constitucional cooperativa entre a ordem estatal e a ordem internacional na sociedade do risco e da informação

concorrência de produtos advindos dos Estados centrais, em detrimento de pequenas e médias empresas nacionais periféricas, bem como às privatizações, entregando-se, sem controle, o poder e a riqueza de empresas estatais a transnacionais, em prejuízo das relações de consumo e dos direitos sociais (especialmente os dos trabalhadores), reduzindo-se salários e amesquinhando-se aposentadorias.

Esse quadro demonstra o nível de desigualdade entre os Estados centrais e os Estados periféricos, bem como das suas respectivas camadas sociais, ao evidenciar uma enorme diferenciação entre incluidos e excluidos que, por mais paradoxal que seja, embora incompatível tanto com a democratização interna (do Estado Democrático de Direito), quanto com a (des)ordem internacional globalizada, ao mesmo tempo, acaba por alavancar tal mencionada desigualdade.

É por isso que se torna pertinente entender-se como ocorre tal diferenciação entre Estados-núcleos e Estados periféricos, de sorte a verificar-se como é que acaba sendo fomentada a desigualdade ao se ter a inclusão destes na rede sistêmica da globalização e, em consequência, sua marginalização, a qual é explicada pelo fato de não alcançarem os padrões globalizados exigidos (políticos, jurídicos, tecnológicos etc) ao, de forma repentina, veem-se obrigados a se inserir nesta nova ordem sem que, em muitos casos, tenham conseguido, ainda, ultrapassar as providências necessárias para a preservação dos direitos humanos/fundamentais em seu território, sequer alinhando-se integralmente com os ditames da etapa evolutiva de um Estado de Bem-Estar-Social (Estado de Previdência) e, assim, deflagrando o fenômeno da chamada modernidade tardia ou um simulacro de modernidade, na expressão de Vieira (1995) bem mencionada por Streck (2004).

Dessa forma, na atualidade do processo de globalização, os Estados-núcleos, cujas principais características se mostram bem arroladas por Barnett (1994), são centros de irradiação de decisões econômico-financeiras, políticas, científico-tecnológicas e culturais, ao passo que os Estados periféricos limitam-se a orbitar impulsionados por essas demandas em torno do centro, de cuja força gravitacional não conseguem escapar, reproduzindo, em certa medida, as tradicionais polarizações existentes no debate estatal, político e desenvolvimentista internacional, tais sejam, Norte-Sul, Oriente-Ocidente, Ricos-Pobres, Centro-Periferia, que se supunham ultrapassadas no cenário mundial ${ }^{6}$.

E isso decorre, sem dúvida, da circunstância de que a globalização, por si só, não tem conduzido a um processo de inclusão, ou melhor, a um processo homogêneo em razão da modernidade tardia - ou mesmo simulacro de modernidade, conforme Vieira (1995) - a que os Estados periféricos (antes acoimados de subdesenvolvidos), como o

\footnotetext{
${ }^{6}$ Há que registrar em tal cenário mundial, outrossim, a paradoxal tendência de "periferização do centro" comentada por Tomaz (2016), mas que, em razão do corte metodológico deste estudo, não será objeto de análise.
} 
Brasil, ainda se encontram vinculados ante o enfraquecimento da Constituição enquanto fator de generalização congruente de expectativas normativas (CALDAS, 1997).

A distinção da realidade desses Estados em relação aos centrais, em que suas desigualdades sociais não foram ainda superadas ou equalizadas dentro do modelo tradicional de exercício da soberania, quer por falta de recursos financeiros, quer por falta de vontade política (vontade de constituição - HESSE, 1983), por si só, implica manifesta disparidade de interesses e, assim, uma posição diferenciada que exige um planejamento estratégico e uma maneira mais adequada de exercício da soberania constitucional para se contornar tais efeitos maléficos globalizantes, aproveitando-se, ao máximo, dos efeitos positivos do processo para um, assim, otimizado desenvolvimento sustentável, porquanto, como há muito esclarecido por Vilanova (1977, p. 24)

A racionalização do processo de desenvolvimento confere a globalização: desenvolvimentos só setoriais desarticulam a composição do conjunto. Requer a politização: só um agente, como o poder, dispõe de substância econômica, financeira, decisão sobre o todo do desenvolvimento, duração e fins que ultrapassam a duração e os fins de indivíduos e, até, de gerações; somente o poder político capacita-se para a programação dessa mudança que, pelo compasso e velocidade, é singela fórmula do progresso dentro da ordem, do Estado liberal democrático. Requer planejamento. Tudo isso, necessita mais Estado e exigindo mais estado, exige mais direito. $O$ desenvolvimento programado apóia-se nas ciências naturais e nas ciências sociais. As ciências, instrumentalmente utilizadas, dão margem às tecnologias. Diríamos, em síntese, que essa transformação rápida da sociedade global apóia-se na política, no direito e na tecnologia.

E é o planejamento estratégico, consubstanciado nas políticas públicas advindas da Carta política de cada Estado (Constituição), que traz sua identidade cultural neste mundo globalizado (HÄBERLE, 2007; VERDÚ, 1998), ou seja, empresta a protoglobalização (ANDREUCCI, 2019; ANDREUCCI; NOHARA, 2011) necessária a si e sua sociedade para não apenas sobreviverem orbitando em torno de interesses hegemônicos econômicos e políticos globais, mas também estarem capacitados, em uma cooperativa parceria entre sociedade e Estado, como igualmente entre Estados com interesses afins, a descobrirem os caminhos até seus interesses, os quais, sob a óptica do Constitucionalismo de resultado, apenas objetivam-se pela concreção dos direitos humanos/fundamentais (MOREIRA NETO, 2009).

Tais novos vínculos estatais identitários considerados a partir do sistema jurídico nesse processo do surgimento da atual comunidade global (protoglobalização) considerados por Teubner (1989) como "identidades múltiplas" deste sistema -, modelados pelos interesses, pelos objetivos e pelas prioridades sociais, há que se 
Efetividade dos direitos humanos e democracia: a soberania constitucional cooperativa entre a ordem estatal e a ordem internacional na sociedade do risco e da informação

ressaltar, somente terão sua construção exitosa se for adotado um planejamento estratégico por parte dos Estados, segundo um arquétipo de exercício da soberania que seja constitucional e cooperativo, adaptado a esta realidade globalizada em que o contraste entre uma modernidade central e uma modernidade periférica, demonstrando o embate de civilizações aos moldes previstos por Huntington (1996), bem como a falta de autonomia das esferas de juridicidade, sobretudo a estatal em definir os conteúdos e os processos de criação e aplicação normativas ${ }^{7}$, possam ser superados de maneira a valorar a igualdade e a dignidade humana como condições para o desenvolvimento sustentável considerado democrático e de Direito.

Para tanto, à luz das lições de Neves (2006, p. 261) expondo o posicionamento teubneriano, tem-se que a "Teoria do Direito é desafiada [...] a incluir em sua semântica e trazer para o centro de suas discussões a questão das ordens jurídicas globais e plurais, estruturalmente acopladas aos respectivos subsistemas da sociedade mundial." No mesmo diapasão, Luhmann (2002, p. 660) assevera que "no hay nada en el plano de la sociedad del mundo que corresponda al acoplamiento estructural del sistema político y del sistema jurídico por la vía de las Constituciones.”

E essa ausência de uma maior projeção externa da soberania constitucional dos Estados, no âmago da hodierna comunidade global, para que se observe apta a um efetivo acoplamento estrutural e estruturante entre os sistemas político e jurídico internacionais (malgrado tal acoplamento já tenha sido projetado para o processo de integração econômica da União Europeia em 2004, enquanto uma Constituição supranacional que acabou sendo rejeitada em 2007 pelos plebiscitos na França e na Holanda), decorre, primeiro, da circunstância de que a ordem mundial globalizada tem como código hipertrófico o ter/não-ter da Economia e, segundo, porque, como lembra com precisão Teubner (2003, p. 13),

Não só a economia é hoje em dia um sistema autônomo no plano global - também a ciência, a cultura, a técnica de saúde, a previdência social, o transporte, o sistema militar, a mídia e o turismo autoreproduzem-se atualmente como 'sistemas mundiais' no sentido de Wallerstein e fazem, dessa maneira, concorrência à política internacional dos Estados nacionais, com sucesso. Mais ainda: enquanto a política apenas atingiu, na forma das "relações internacionais", um estado de "proto-globalidade" - quer dizer, não muito mais do que relações intersistêmicas entre unidades nacionais com elementos transnacionais relativamente fracos -, outros subsistemas

\footnotetext{
${ }^{7}$ A visão pragmático-sistêmica de Luhmann (2002), com os desdobramentos teoréticos de Neves (2006) e Teubner (2003), bem explica essa crise quando mostra a hipertrofia do código (ter/não ter) da Economia sobre os códigos binários de atuação dos sistemas jurídico (lícito/ilícito) e político (poder/nãopoder ou governo/oposição).
} 
sociais já começaram a formar uma autêntica sociedade mundial, ou melhor, uma quantidade fragmentada de sistemas mundiais distintos. ${ }^{8}$

\section{É por isso que Bolzan de Morais (2011, p. 95) afirma a importância da Constituição}

para o reconhecimento e desenvolvimento do direito humanitário, mesmo sem que saibamos exatamente e com certeza sobre qual o espaço geográfico incidirá o regramento constitucional - o nacional, o local, o regional, o mundial(?) - ou quais mecanismos que são necessários constituir para torná-lo apto a produzir os efeitos pretendidos...

Assim, preleciona que o "seu papel (da constituição) não está terminado, mesmo que esteja passando por uma reformulação profunda, produto de uma realidade nova que impõe seja ordenada levando-se em consideração o seu cunho aberto e universalizado." (BOLZAN DE MORAIS, 2011, p. 94).

A emergência de centros heterárquicos, ou seja, centros de poder produtores de normas que concorrem com o Direito produzido pelo Estado nacional, que caracteriza o fenômeno globalizante, às escâncaras, expõe a crise de unidade, e mesmo de autonomia, dos sistemas que se inserem tanto no ambiente normativo interno, quanto na ordem internacional, havidos, todos eles, além e sobretudo, da Política, da Economia e do próprio Direito.

Divisa-se, portanto, na ordem internacional globalizada, uma policontextualidade alavancada a partir de operações transjuncionais (NEVES, 2006), o que, a bem da verdade, assegura a sua existência a par de não constituir um sistema social diferenciado. Por isso, prossegue Neves propugnando, enfim, pela compatibilidade da concorrência entre o sistema jurídico do Estado Democrático de Direito e o pluralismo jurídico da sociedade mundial afirmando que

Deve-se observar que a polivalência das operações transjuncionais pressupõe a bivalência dos códigos dos respectivos sistemas. Mediante essas operações é possível "passar de uma contextura (uma distinção 'positivo/negativo') para uma outra e marcar, a cada vez, quais as diferenças que se aceitam ou se rejeitam para determinadas operações”. A policontextualidade implica não somente que haja operações transjuncionais entre o código "lícito/ilícito" do sistema jurídico do Estado Democrático de Direito e outros tipos de códigos sociais

\footnotetext{
${ }^{8}$ É preciso, todavia, não se olvidar, como aqui já ressaltado a partir do pensamento de Bolzan de Morais (2011), Castells (2002) e Zagrebelsky (2011), da existência também de núcleos heterárquicos nocivos e com atuação igualmente voltada para concorrer com o poder estatal, como, por exemplo, redes criminosas internacionais para tráfico de entorpecentes, órgãos, crianças, mulheres, armas, capital ilícito, bem como corrupção e cooptação de agências regulatórias em prol de interesses particulares e ilícitos.
} 
Efetividade dos direitos humanos e democracia: a soberania constitucional cooperativa entre a ordem estatal e a ordem internacional na sociedade do risco e da informação

\begin{abstract}
binários ("ter/não-ter”, "poder/não-poder”, "verdadeiro/falso", "transcendente/imanente, "amor/desamor", "belo/feio", "consideração/desprezo", etc.), mas também que ocorram operações polivalentes entre o código "lícito/ilícito" sob o qual o referido sistema opera e outras manifestações do código binário do direito. Essas, por seu turno, não se reduzem nem àqueles códigos jurídicos que se afirmam, respectivamente, em outros sistemas jurídicos estatais segmentariamente diferenciados, nem ao código binário que se apresenta no direito internacional público, mas incluem igualmente os códigos binários específicos das ordens jurídicas globais plurais. Quer dizer: a referência à unidade não trivial, complexa e múltipla do sistema jurídico do Estado Democrático de Direito não exclui uma pluralidade de outras ordens jurídicas que estejam em relações permanentes de concorrência com esse sistema; portanto, não é, em princípio, incompatível com o pluralismo jurídico da sociedade mundial (NEVES, 2006, p. 265).
\end{abstract}

$\mathrm{Na}$ escolha de conteúdos e procedimentos, que tradicionalmente marcou a autonomia normativista do Estado nacional, a função bivalente do código binário do Direito se intensifica em defesa de sua unidade na medida em que ela mediatiza, tanto internamente, como na sociedade/comunidade global, a marcação dos referidos conteúdos e procedimentos pelo filtro do outro código inclusão/exclusão, de modo a privilegiar aqueles (conteúdos e procedimentos) que satisfaçam a igualdade e o princípio da dignidade humana a fim de que os direitos humanos/fundamentais possam aparecer na policontextualidade como limite da capacidade de aprendizagem e condição de possibilidade das comunicações deflagradas no plano interno ou daquelas objeto das operações transjuncionais, claramente maximizadas pelos avanços tecnológicos que marcam a dita sociedade da informação dromocrática (VIRILIO, 1996).

Quando a função binária inclusão/exclusão mediatiza o irrompimento de operações por todos os sistemas, ela está guindada ao status de um meta-código (LUHMANN, 2002), decorrendo, desde aí, a importância da Constituição como locus de fundamentabilidade dos direitos humanos (e de outras naturezas, como os civis, os sociais, os assistenciais etc.), permitindo a exata mediação de sua defesa, seja no plano interno, por meio de acoplamentos estruturais e estruturantes entre os sistemas, seja apontando o norte para as operações inter-sistêmicas no âmbito da transjuncionalidade heterárquica, na ordem global (NEVES, 2006).

\title{
4 CONCLUSÃO
}

Realmente, apesar de toda a "constitucionalização do Direito Internacional", como se assiste no processo de integração e unificação da Europa, e de toda "internacionalização do Direito Constitucional”, com a abertura das Constituições para 
acolher normas de Direito Internacional, como princípios e tratados, ainda se divisa no Direito nacional o ponto de partida para a existência e a produção do sistema internacional, em projeção de uma soberania constitucional cooperativa, inclusive à luz da concepção de global governance alinhada à acepção lata de multitude, rumo a um Direito geral de cooperação häberlesiano entre Estados (e entre estes e suas sociedades) no seio de uma comunidade global comprometida com a realização dos direitos humanos/fundamentais.

É inegável que o processamento dromocrático de comunicações intersistêmicas na comunidade global, cujo resultado é a criação de novos polos heterárquicos, policêntricos, multilaterais e, assim, multifacetados (multi-stakeholderism), tem-se erigido em detrimento do tradicional desempenho da função sistêmica da Constituição de acoplamento estrutural e estruturante entre Direito (lícito/ilicito), Economia (ter/não-ter) e Política (poder/não-poder), de modo a impedir uma salutar inter-referência entre si e, assim, ter-se um canal cooperativo de equalização dos interesses recíprocos no concerto democrático tradicional, forçando um novo arranjo por parte dos Estados, segundo uma visão dinâmica da Constituição enquanto um processo ideológico-cultural.

A seu turno, as relações entre os polos heterárquicos desenvolvem-se por meio de operações transjuncionais que prejudicam a concreção dos direitos humanos e/ou fundamentais, tal qual acontece na ordem constitucional dos Estados à luz da concepção tradicional de exercício da sua soberania estatal, em claro detrimento de uma maior inclusão social, o qual somente pode ser contornado mediante uma dinâmica ideológico-processual constitucional, a prestigiar e fomentar sua programação política nas estruturas sociais que visa a reger de forma preponderante, criando um engajamento intenso dos a elas concernidos em um processo com a abertura de canais para sua participação e cooperação.

Os novos vínculos estatais identitários considerados a partir do sistema jurídico ao longo do processo de globalização (protoglobalização), a sua vez, somente terão êxito para uma efetiva inclusão social, mediante um planejamento estratégico, por parte dos Estados, que leve em consideração, de um lado, uma governança resiliente concertada (global e regulatória) que se mostre adaptativa/transformadora das estruturas organizacionais e procedimentais dos distintos atores, afastando aqueles considerados nocivos em um processo dialógico definidor dos conteúdos e dos procedimentos a serem discutidos, e, de outro, o exercício da soberania constitucional devidamente conformado para um Direito global, sob uma nova forma de multilateralismo, ou seja, complementado por um multi-stakeholderism heterárquico e cooperativo para ampla efetivação dos direitos humanos/fundamentais. 
Efetividade dos direitos humanos e democracia: a soberania constitucional cooperativa entre a ordem estatal e a ordem internacional na sociedade do risco e da informação

\section{REFERÊNCIAS}

ANDREUCCI, Álvaro Gonçalves Antunes. O grito: globalização, retrocesso ou... diálogos possíveis acerca da integração, da sustentabilidade e da democracia. In: MATA DIZ, Jamile Bergamaschine; CALDAS, Roberto Correia da Silva Gomes; BRAGA, Sérgio Pereira (org.). Globalização, desenvolvimento sustentável e efetividade da justiça. Belo Horizonte: Arraes Editores, 2019. Disponível em: http://domhelder.edu.br/wp-content/uploads/2020/03/735_GLOBALIZACAODESE NVSUSTEFETIVIDADEJUSTICA_EBOOKPDF.pdf. Acesso em: 11 fev. 2020.

ANDREUCCI, Álvaro Gonçalves Antunes; NOHARA, Irene Patrícia. Globalização e sustentabilidade no Poder Judiciário: desafios para uma visão crítica da complexidade. In: CONPEDI. Encontro Nacional do Conpedi. Florianópolis: Fundação Boiteux, 2011. v. 1. p. 303-318. Disponível em: https://s3.amazonaws.com/conpedi2/anteriores/XX+En contro+Nacional+-+FUMEC+Belo+Horizonte+-+MG $+(22 \% 2 \mathrm{C}+23 \% 2 \mathrm{C}+24+\mathrm{e}+25+$ de+junho+de+2011).pdf. Acesso em: 11 fev. 2020.

BARNETT, Jeffrey R. Exclusion as national security policy. Parameters: Journal of the US Army War College, Carlisle Barracks, v. 24, p. 51-65, spring 1994.

BAUMAN, Zygmunt; DONSKIS, Leonidas. Maldad líquida: vivir sin alternativas. Tradução de Albino Santos Mosquera. Ciudad Autónoma de Buenos Aires: Paidós, 2019.

BENEDEK, Wolfgang. Muti-stakeholderism in the development of International Law. In: FASTENRATH, Urilch et al. (ed.). From bilateralism to community interest: essays in honour of Judge Bruno Simma. New York: Oxford University Press, 2011. p. 201 210. Disponivel em: https://books.google.com.br/books?id=Wv6BCUOqu78C\&pg= PA201\&lpg=PA201\&dq=BENEDEK,+Wolfgang.+Muti-stakeholderism+in+the+develop pment ${ }^{+}$of + International + Law. $\&$ source $=b l \& o t s=z$ CwnjFSMNO\&sig $=A C f U 3 U 1 \mathrm{kC} z$ jimP hUV-pR5p-_xkF5U9djEQ\& $\&$ l=pt-BR\&sa $=X \& v e d=2 a h U K E w i H k P a C l d L p A h X Y C r k G$ HU3qCg8Q6AEwBHoECAoQAQ\# $\mathrm{v}^{=}$onepage $\& \mathrm{q}=$ BENEDEK\%2C\%20Wolfgang. $\% 20$ Muti-stakeholderism\%20in\%20the\%20development\%20of\%20International\%20Law. $\& f=$ false. Acesso em: 22 abr. 2020.

BODIN, Jean. Los seis libros de la República. Caracas: Instituto de Estudios Políticos/ Facultad de Derecho. Universidad Central de Venezuela, 1966.

BOLZAN DE MORAIS, José Luis. As crises do Estado e da Constituição e a transformação espaço-temporal dos direitos humanos. 2. ed. Porto Alegre: Livraria do Advogado, 2011.

BOLZAN DE MORAIS, José Luis; NASCIMENTO, Valéria Ribas do. Constitucionalismo e cidadania: por uma jurisdição constitucional democrática. Porto Alegre: Livraria do Advogado, 2010. 
BROWNING, Gary; KILMISTER, Andrew. Hardt and Negri: Empire, Multitude and Globalisation. In: BROWNING, Gary; KILMISTER, Andrew. Critical and post-critical political economy. London: Palgrave Macmillan, 2006. p. 169-192.

CALDAS, Roberto Correia da Silva Gomes. O papel da Constituição sob uma visão autopoiética do Direito. Revista dos Tribunais - Cadernos de Direito Constitucional e Ciência Política, São Paulo, v. 5, n. 20, p.213-228, jul./set. 1997.

CALDAS, Roberto Correia da Silva Gomes. Um estudo sobre a governança global e a governança europeia: convergências em prol de um sistema regulatório participativo. In: MATA DIZ, Jamile Bergamaschine; SILVA, Alice Rocha da; TEIXEIRA Anderson Vichinkeski (org.). Integração, Estado e governança. Pará de Minas: Virtual Books, 2016. Disponível em: http://www.uit.br/mestrado/publicacoes.html. Acesso em: 11 jul. 2017.

CALDAS, Roberto Correia da Silva Gomes; MARTINS, Thiago Penido. Princípios do Equador e Governança Regulatória nas contratações públicas sustentáveis: implicações nas desapropriações. RBEP - Revista Brasileira de Estudos Políticos, v. 112, p. 112 142, jan./jul. 2016. Disponível em: https://pos.direito.ufmg.br/rbep/index.php/rbep/ article/view/P.0034-7191.2016V112P183/344. Acesso em: 22 abr. 2020.

CALDAS, Roberto Correia da Silva Gomes; FREITAS, Sandra Neder Thomé de. A governança e a cidadania participativa na União Europeia. Revista Jurídica UNICURITIBA, Curitiba, v. 50, n. 1, p. 325-342, 2018. Disponível em: http://revista.unicuritiba.edu.br/index.php/RevJur/article/view/3203/371371724.

Acesso em: 22 abr. 2020.

CASTELLS, Manuel. O poder da identidade. São Paulo: Paz e Terra, 2001.

CASTELLS, Manoel. A sociedade em rede. 6. ed. São Paulo: Paz e Terra, 2002.

CAVALCANTI, Amaro. Regimen federativo: a republica bazileira. Rio de Janeiro: Imprensa Nacional, 1900.

CRUTZEN, Paul J.; STOERMER, Eugene F. The "Anthropocene". Global Change Newsletter, Stockholm, n. 41, p. 17-18, May 2000. Disponível em: http://www.igbp.net/download/18.316f18321323470177580001401/1376383088452 /NL41.pdf. Acesso em: 16 jan. 2020.

DWORKIN, Ronald. Levando os direitos a sério. 3. ed. São Paulo: WMF Martins Fontes, 2010.

FERRAJOLI, Luigi. A soberania no mundo moderno: nascimento e crise do Estado nacional. São Paulo: Martins Fontes, 2002.

GROTIUS, Hugo. O direito da guerra e da paz. Tradução de Ciro Mioranza. 2. ed. Ijuí: Editora Unijuí - Fondazione Cassamarca, 2005. v. 1. 
Efetividade dos direitos humanos e democracia: a soberania constitucional cooperativa entre a ordem estatal e a ordem internacional na sociedade do risco e da informação

GUERRA FILHO, Willis Santiago. Autopoiese do Direito na sociedade pós-moderna: introdução a uma teoria social sistêmica. Porto Alegre: Livraria do Advogado, 1997.

HÄBERLE, Peter. Estado constitucional cooperativo. Tradução Marcos Augusto Maliska e Elisete Antoniuk. Rio de Janeiro: Renovar, 2007.

HABERMAS, Jürgen. A constelação pós-nacional: ensaios políticos. São Paulo: Litera Mundi, 2001.

HARDT, Michael; NEGRI, Antonio. Empire. Cambridge (MA): Harvard University Press, 2000.

HELLER, Hermann. La Soberania: contribuición a la teoría del derecho estatal y del derecho internacional. Tradução Mario de la Cueva. México: Fondo de Cultura Económica, 1995.

HESSE, Konrad. Escritos de Derecho Constitucional (selección). Madri: Centro de Estudios Constitucionales, 1983.

HOBSBAWM, Eric. Nações e nacionalismo desde 1970: programa, mito e realidade. Rio de Janeiro: Paz e Terra, 1990.

HOBSBAWM, Eric. A era dos extremos: o breve século XX: 1914 - 1991. 2. ed. São Paulo: Companhia das Letras, 1997.

HOFFMANN-RIEM, Wolfgang. Autorregulação, autorregulamentação e autorregulamentação regulamentada no contexto digital. Tradução de Luís Marcos Sander. Revista da AJURIS, Porto Alegre, v. 46, n. 146, p. p. 529-554, jun. 2019. Disponível em: http://ajuris.kinghost.net/OJS2/index.php/REVAJURIS/article/view/ 1048/Ajuris_146\%20-\%20DT20. Acesso em: 11 set. 2019.

HUNTINGTON, Samuel P. O choque de civilizações e a recompensa da ordem mundial. Rio de Janeiro: Objetiva, 1996.

KANT, Immanuel. A paz perpétua e outros opúsculos. Lisboa: edições 70, 1995.

KELSEN, Hans. Teoria Geral do Direito e do Estado. São Paulo: Martins Fontes, 1992.

LAFER, Celso. A soberania e os direitos humanos. Lua Nova, São Paulo, n. 35 , p. 137 148, 1995. Disponível em: http://www.scielo.br/scielo.php?script=sci_arttext\&pid =S0102-64451995000100006\&lng=en\& nrm=iso. Acesso em: 22 abr. 2020.

LOURENÇO, Nelson. Globalização e glocalização. O difícil diálogo entre o global e o local. Mulemba - Revista Angolana de Ciências Sociais, Luanda, v. 4, n. 8, p. 17-31, nov. 2014. Disponível em: https://journals.openedition.org/mulemba/203. Acesso em: 11 set. 2019. 
LOURENÇO, Nelson. Sociedade global, risco e segurança. RECHTD - Revista de Estudos Constitucionais, Hermenêutica e Teoria do Direito, São Leopoldo, v. 11, n. 2, p. 211-219, maio/ago. 2019. Disponível em: http://revistas.unisinos.br/index.php/RECHTD/article/view/rechtd.2019.112.05/607 47315. Acesso em: 11 set. 2019.

LUHMANN, Niklas. El derecho de la sociedad. México: Universidad Iberoamericana, 2002.

MAIA, Gretha Leite. Revisitando quatro categorias fundamentais: Estado de Direito, Estado Liberal, Estado Social e Democracia. Nomos - Revista do Programa de PósGraduação em Direito - UFC, Fortaleza, v. 31, n. 2, p. 29-41, jul./dez. 2011. Disponível em: http://www.periodicos.ufc.br/nomos/article/view/384/366. Acesso em: 16 out. 2017.

MATA DIZ, Jamile Bergamaschine; CALDAS, Roberto Correia da Silva Gomes. Contratos administrativos à luz de novas formas de gestão e da sustentabilidade: por uma concretização do desenvolvimento sustentável no Brasil. A\&C - Revista de Direito Administrativo \& Constitucional, Belo Horizonte, v. 16, n. 65, p. 249-275, jul./set. 2016. Disponível em: http://www.revistaaec.com/index.php/revistaaec/article/view/ 267/632. Acesso em: 17 set. 2019.

MOREIRA NETO, Diogo de Figueiredo. O paradigma do resultado. In: CARLIN, Volnei Ivo (org.). Grandes temas do Direito Administrativo: Homenagem ao Professor Paulo Henrique Blasi. Florianópolis: Millenium, 2009. p. 215-228.

NEVES, Marcelo. Entre Têmis e Leviatã: uma relação difícil: o Estado Democrático de Direito a partir e além de Luhmann e Habermas. São Paulo: Martins Fontes, 2006.

OLSSON, Giovanni; LAVALL, Tuana Paula. Os limites e as possibilidades do Estadonação na promoção do trabalho decente no marco da Agenda 2030 da Organização das Nações Unidas. Revista Opinião Jurídica, Fortaleza, v. 18, n. 28, p. 115-144, maio/ago. 2020. Disponível em: https://periodicos.unichristus.edu.br/opiniaojuridica/article/ view/2589/1096. Acesso em: 22 abr. 2020.

ONU - Organização das Nações Unidas. Agenda 2030. 2015. Disponível em: https://nacoesunidas.org/pos2015/agenda 2030/. Acesso em: 6 set. 2019.

ONU - Organização das Nações Unidas. PNUD - Programa das Nações Unidas para o Desenvolvimento. Rede Brasil do Pacto Global. 2019. Disponível em: https://www.pactoglobal.org.br/assets/docs/cartilha_pacto_global.pdf. Acesso em: 17 jun. 2019.

PAGLIARINI, Alexandre Coutinho. Direitos humanos, constituição e democracia na nação e no mundo. Nomos - Revista do Programa de Pós-Graduação em Direito UFC, Fortaleza, v. 25, p. 21-32, 2006. Disponível em: 
Efetividade dos direitos humanos e democracia: a soberania constitucional cooperativa entre a ordem estatal e a ordem internacional na sociedade do risco e da informação

http://www.periodicos.ufc.br/nomos/ article/view/20021/30674. Acesso em: 16 out. 2017.

ROSENAU, James N. Governança, ordem e transformação na política mundial. In: ROSENAU, James N.; CZEMPIEL, Ernst-Otto (org.). Governança sem governo: ordem e transformação na política mundial. Tradução Sérgio Bath. Brasília: Ed. Unb; São Paulo: Imprensa Oficial do Estado, 2000. p. 11-46. Disponível em: http://professor.pucgoias.edu.br/SiteDocente/admin/arquivosUpload/17553/material /2.4\%20COMPLEMENTAR\%20-\%20Rosenau\%20\&\%200tto\%20-

\%20Governan\%C3\%A7a\%20sem\%20governo.pdf. Acesso em: 5 nov. 2017.

STRECK, Lenio Luiz. Hermenêutica jurídica e(m) crise: uma exploração hermenêutica da construção do Direito. 5. ed. Porto Alegre: Livraria do Advogado, 2004.

TEUBNER, Gunther. A Bukowina global: sobre a emergência de um pluralismo jurídico transnacional. Impulso - Revista de Ciências Sociais e Humanas, Piracicaba, v. 14, n. 33, p. 9-31, jan./abr. 2003. Disponível em: https://webcache.googleusercontent.com/search?q=cache:QAZnXKHZyQYJ:https://sip osg.furg.br/selecao/download/1065/Teubner2003_PluralismoJrco.pdf $+\& c d=1 \&$ hl=ptBR\&ct $=\mathrm{clnk \& gl}=$ br. Acesso em: 16 out. 2017.

TEUBNER, Gunther. O direito como sistema autopoiético. Tradução José Engrácia Antunes. Lisboa: Fundação Calouste Gulbenkian, 1989.

TOMAZ, Carlos Alberto Simões de. Constituição, política e a ordem internacional heterárquica: uma reflexão a partir da visão pragmático-sistêmica de Luhmann. Curitiba: Editora CRV, 2011.

TOMAZ, Carlos Alberto Simões de. Democracia e jurisdição: entre o texto e o contexto! 2. ed. São Paulo: Editora Baraúna, 2016.

TOMAZ, Carlos Alberto Simões de; LAGES, Cintia Garabini. (Re)pensando o arranjo democrático na modernidade tardia. Conpedi Law Review, Florianópolis, v. 1, n. 14, 2015, p. 28-57. Disponível em: https://www.indexlaw.org/index.php/conpedireview/ article/view/3516/3026. Acesso em: 22 abr. 2020.

TOMAZ, Carlos Alberto Simões de; MATA DIZ, Jamile Bergamaschine; CALDAS, Roberto Correia da Silva Gomes. "Governo versus Jurisdição": aportes para compreensão da crise nas democracias contemporâneas. Revista Brasileira de Políticas Públicas, Brasília, v. 9, n. 3, p.349-373, 2019. Disponível em: https://www.publicacoesacademicas.uniceub.br/RBPP/article/view/6320/pdf. Acesso em: 22 abr. 2020.

VERDÚ, Pablo Lucas. Teoría de la Constituición como ciencia cultual. Madrid: Dykinson, 1998. 
VIEIRA, José Ribas. Teoria do Estado. Rio de Janeiro: Lúmen Júris, 1995.

VILANOVA, Lourival. Fundamentos do Estado de Direito. Revista de Direito Público, São Paulo, v. 8, n. 43/44, p. 21-31, jul./dez. 1977.

VIRILIO, Paul. Velocidade e política. Tradução Celso M. Paciornik. São Paulo: Estação da Liberdade, 1996.

VOIGT, Rüdiger. Quem é o soberano? Sobre um conceito-chave na discussão sobre o Estado. Revista de Sociologia e Política, Curitiba, v. 21, n. 46, p. 105-113, jun. 2013. Disponível em: https://revistas.ufpr.br/rsp/article/view/34460/21371. Acesso em: 16 out. 2017.

ZAGREBELSKY, Gustavo. El derecho dúctil: ley, derechos, justicia. Tradução Marina Gascón. Madrid: Editorial Trotta, 2011.

\section{NOTA}

Declaramos que o artigo intitulado "EFETIVIDADE DOS DIREITOS HUMANOS E DEMOCRACIA: A SOBERANIA CONSTITUCIONAL COOPERATIVA ENTRE A ORDEM ESTATAL E A ORDEM INTERNACIONAL NA SOCIEDADE DO RISCO E DA INFORMAÇÃO”, submetido à Revista Opinião Jurídica, representa fruto direto das pesquisas desenvolvidas pelos autores, sobretudo no âmbito das atividades da Rede de Pesquisa "Integração, Estado e Governança", tendo ambos (membros permanentes da referida Rede) realizado, concomitantemente, as tarefas de seu planejamento, execução e revisão da seguinte forma: 1) Roberto Correia da Silva Gomes Caldas: desenvolveu de forma mais específica a parte relativa à soberania constitucional cooperativa e à efetividade dos direitos humanos/fundamentais na sociedade do risco e da informação; e 2) Carlos Alberto Simões de Tomaz: desenvolveu de forma mais específica a parte relativa à projeção da soberania na sociedade heterárquica, em âmbito interno e internacional.

\section{Como citar este documento:}

CALDAS, Roberto Correia da Silva Gomes; TOMAZ, Carlos Alberto Simões de. Efetividade dos direitos humanos e democracia: a soberania constitucional cooperativa entre a ordem estatal e a ordem internacional na sociedade do risco e da informação. Revista Opinião Jurídica, Fortaleza, v. 18, n, 29, p. 49-76, set./dez. 2020. 